\title{
Electrochemical Promotion of Catalysis
}

\author{
György Fóti, Ivan Bolzonella, Justyna Eaves, and Christos Comninellis*
}

\begin{abstract}
Recent progress made in our laboratory in the field of electrochemical promotion of heterogeneous catalytic gas reactions is presented. The phenomenon consists of non-Faradaic modification of the catalytic reaction rate as the result of electrochemical polarization of the interface between the catalyst and the solid electrolyte support. Two main aspects are addressed, the description of the phenomenon and the development of bipolar cell configurations suitable for practical applications. It is shown that the necessary condition to achieve electrochemical promotion is the formation of a double layer at the catalyst/gas interface by mechanism of ion backspillover from the solid electrolyte support. Electrochemical promotion is only feasible in an adequate temperature range, limited by the mobility and the lifetime of the promoting ion, and it is favored by high porosity and low film thickness of the catalyst. On the application side, two new cell designs have been developed, a ring-shaped and a multiple-channel configuration, both operated in bipolar polarization mode. The ring-shaped cell is shown to be almost free of current bypass. Feasibility of electrochemical promotion is successfully demonstrated with both configurations. Realization of efficient bipolar cell configurations for electrochemical promotion is very promising in view of future applications in dispersed catalytic systems.
\end{abstract}

Keywords: Bipolar electrochemical cell · Catalysis · Current bypass · Electrochemical promotion · Gas-phase reactions

\section{Introduction}

Electrochemical promotion (EP) means the electrically controlled modification of heterogeneous catalytic activity and/or selectivity. Discovered some fifteen years ago [1], the phenomenon has mainly been investigated in gas-phase reactions over metal and metal oxide catalysts [2][3].

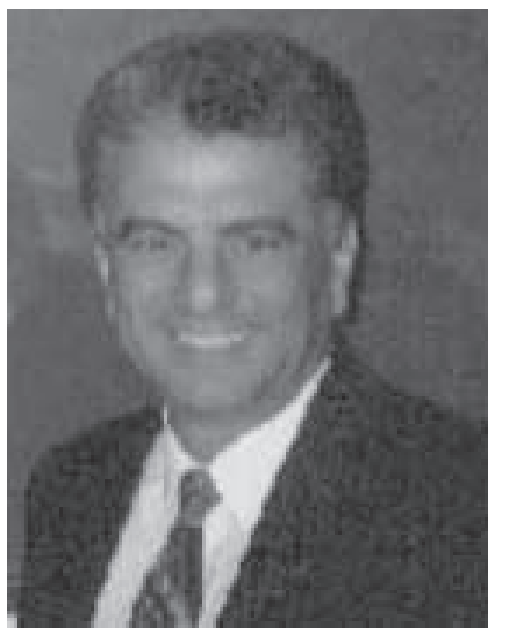

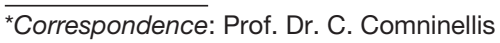
Ecole Polytechnique Fédérale de Lausanne Faculté des Sciences de Base

Institut de Sciences des Procédés chimiques et biologiques

$\mathrm{CH}-1015$ Lausanne

Tel.: +41216933674

Fax: +4121693 3190

E-Mail: christos.comninellis@epfl.ch

http://dcwww.epfl.ch/lgrc/
The catalyst, which is an electron conductor, is deposited in form of a porous thin film on a solid electrolyte support, which is an ion conductor at the temperature of the catalytic reaction. Application of an electric potential on the catalyst/support interface or, which is equivalent, passing an electric current between catalyst and support causes a concomitant change also in the properties of the adjacent catalyst/gas interface, where the catalytic reaction takes place. This results in an alteration of the catalytic activity controllable with the applied potential or current.

Typical catalytic reaction rate transients due to electrochemical promotion are shown in Fig. 1. The example is the combustion of ethylene with oxygen at $375{ }^{\circ} \mathrm{C}$ over $\mathrm{RuO}_{2}$ catalyst interfaced with yttria-stabilized zirconia (YSZ) solid electrolyte, which is an $\mathrm{O}^{2-}$ conductor at this temperature. Application of an anodic current in this system means that the solid electrolyte supplies $\mathrm{O}^{2-}$ ions to the $\mathrm{RuO}_{2} / \mathrm{YSZ}$ interface and the catalyst serves as the collector of electrons. As seen in Fig. 1, a huge increase in reaction rate is observed during anodic current application. The effect is by orders of magnitude higher than the rate of $\mathrm{O}^{2-}$ supply toward the catalyst which is, after Faraday's law, equal to the maximum possi- ble rate enhancement due to electrochemical oxidation of ethylene. It is evident that electrochemical promotion is clearly not a Faradaic electrochemical reaction. This statement is further confirmed by the experimental fact that even a chemical reduction (e.g. reduction of $\mathrm{NO}$ with propylene over $\mathrm{Rh} / \mathrm{YSZ}$ catalyst, see later) may be promoted by application of anodic (i.e. electrochemically oxidizing) current. Note that Fig. 1 illustrates the general case when the steady-state opencircuit reaction rate after current interruption, $r$, is significantly higher than its initial value before current application, $r_{\mathrm{o}}$. This irreversibility, first reported from our laboratory [4] and called permanent promotion, is attributed to current-assisted chemical modification of the catalyst surface.

The experimental set-up used for kinetic measurements is described in detail elsewhere [5]. The most important part is the electrochemical cell placed in a temperature-controlled reactor fed with the reactive gas mixture. The simplest electrochemical cell for EP experiments is of the single-pellet type where the working electrode (catalyst) and the counter-electrode (usually a porous gold film) are deposited on the two sides of a thin solid electrolyte pellet. In this configuration, widely used for fundamental studies of 


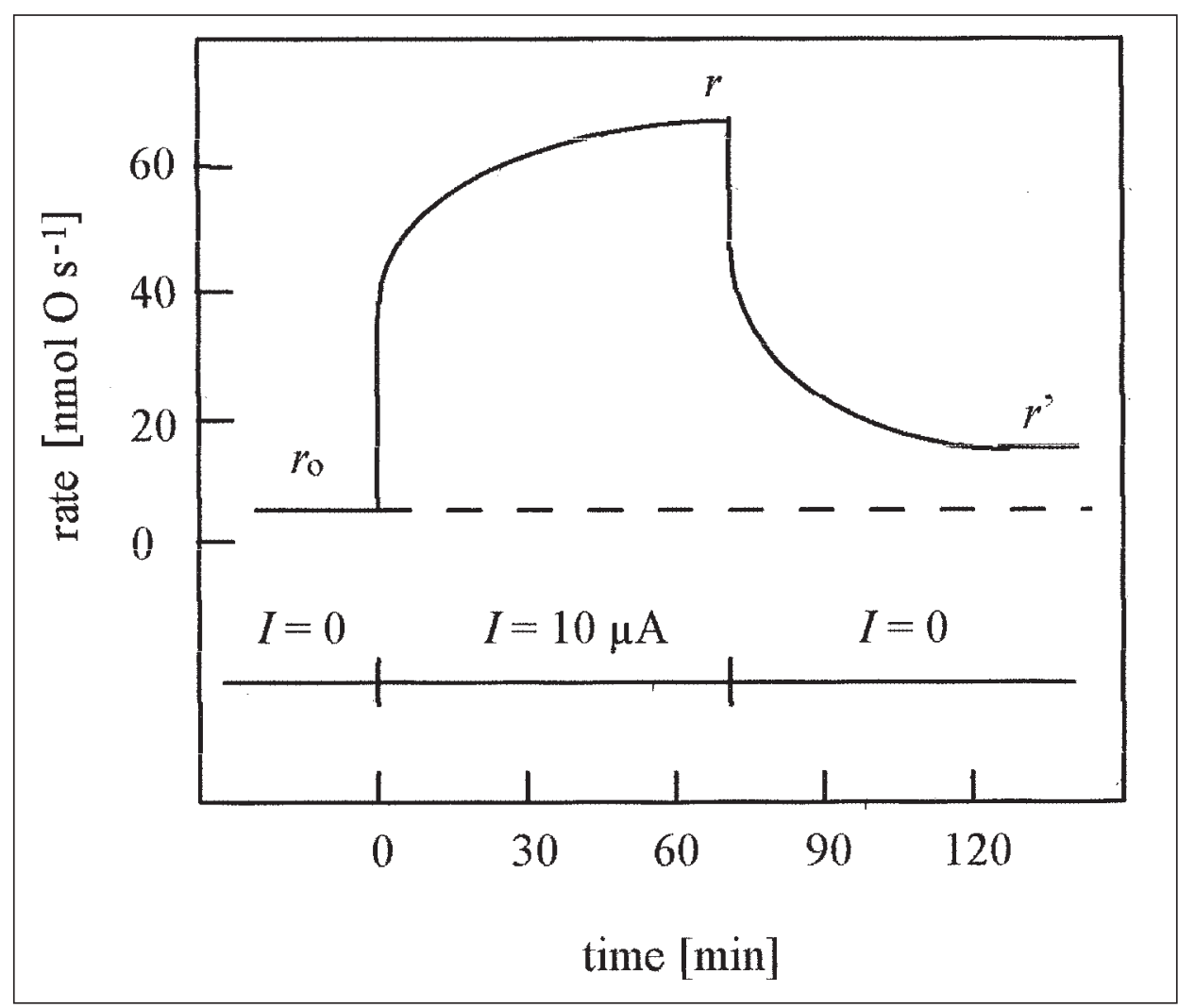

the phenomenon, the catalyst itself is a feeder electrode hence it must be directly connected (e.g. with a fine gold wire) to the potentiostat. Such a configuration is obviously inadequate for practical applications with dispersed catalysts. The only viable way to achieve electrochemical promotion in dispersed systems implies indirect bipolar polarization of the cata- lyst in a suitable electrochemical cell. Two generations of advanced bipolar cell configurations, a ring-shaped and a multiple-channel cell, illustrated together with a tubular reactor assembly in Fig. 2, have been developed in our laboratory using YSZ solid electrolyte; see section 3 for details. These bipolar cells may be regarded as the first successful steps to-

Fig. 1. Electrochemical promotion of ethylene combustion over $\mathrm{RuO}_{2} / \mathrm{YSZ}$ catalyst. Schematic representation of evolution of the reaction rate due to anodic current application of $10 \mu$ A during $70 \mathrm{~min}$. Maximal electrochemical rate increase from Faraday's law: $I / 2 F=$ 52 pmol O s ${ }^{-1}$. Experimental conditions: atmospheric reactor, $p_{\mathrm{C}_{2} \mathrm{H}_{4}}=100 \mathrm{~Pa}, p_{\mathrm{O}_{2}}=12 \mathrm{kPa}$, $\dot{v}=175 \mathrm{ml} \mathrm{min}^{-1} \mathrm{STP}, T=380{ }^{\circ} \mathrm{C}$.

Fig. 2. Left: tubular reactor assembly and furnace used with bipolar cell configurations. 1: Pyrex tube $(\varnothing=25 / 18 \mathrm{~mm}$, length: $400 \mathrm{~mm}$, volume: $150 \mathrm{ml}$ ); 2: electro-chemical cell. Right: bipolar electrochemical cells. a: ring-shaped cell configuration; $\mathbf{b}$ : multiple-channel cell configuration. 
wards achievement of electrochemical promotion with highly dispersed catalysts.

In this short paper, first a brief phenomenological description of electrochemical promotion will be given with special emphasis on its functional analogy with classical promotion of catalysis, then results from our laboratory on the development of new bipolar cell configurations in view of future industrial applications will be presented.

\section{The Phenomenon of Electrochemical Promotion}

In any electrochemical cell suitable for EP experiments several interfaces may be identified, such as electrode/electrolyte interfaces, electrode/gas interfaces, and three-phase boundaries (tpb). Due to the different mechanism of electric conductivity in electrodes and electrolyte, polarization of the catalyst by current application involves charge transfer reactions and a consequent charge separation, all localized, at a first glance, at the electrode/electrolyte interfaces and/ or at the three-phase boundaries. The resulting promotion of catalytic activity reveals, however, modification also of another interface, namely the gas-exposed catalyst surface where the heterogeneous gas reactions occur. In fact, the key to understanding electrochemical promotion is to elucidate the mechanism of how the effect of polarization propagates from one interface to the other.

It is believed that electrochemical promotion of catalysis, similar to usual (chemical) promotion and to metal-support interactions in heterogeneous catalysis, is related to spillover-backspillover phenomena. This latter can be described as the migration of adsorbed species from one phase on which they easily adsorb (donor) to another phase where they may not adsorb directly (acceptor). By this mechanism a seemingly inert material can acquire catalytic activity. A general reaction scheme of oxygen spillover in a purely (not electro-) catalytic system [6] may be formulated as follows, see also Fig. 3a.

Fig. 3. a: Schematic representation of the mechanism of oxygen spillover in a purely catalytic system; symbols as in Eqns 1. b: Schematic representation of the mechanism of electrochemical promotion under anodic current application via backspillover of charged promoting species $\left(\mathrm{O}^{2-}\right)$.

$$
\begin{aligned}
& \mathrm{O}_{2}+2 \mathrm{D} \leftrightarrows 2 \mathrm{O} \cdot \mathrm{D} \\
& \mathrm{A}+\mathrm{O} \cdot \mathrm{D} \rightarrow \mathrm{D}+\mathrm{O} \cdot \mathrm{A} \\
& \mathrm{O} \cdot \mathrm{A}+\mathrm{B} \rightarrow \mathrm{C} \\
& \mathrm{R}+\mathrm{C} \rightarrow \mathrm{P}+\mathrm{B}
\end{aligned}
$$

Eqn. 1a describes the dissociative adsorption and recombination of oxygen on a donor $\mathrm{D}$. The transfer between the donor $\mathrm{D}$ and acceptor $\mathrm{A}$ is given by Eqn. $1 \mathrm{~b}$. The spillover oxygen $(\mathrm{O})$ is a mobile species present on the acceptor surface without being associated with a particular surface site. These mobile spillover species may then interact with a, catalytically inactive, surface site B (Eqn. 1c) forming a new site $C$ which may be active. Eqn. $1 d$ represents the catalytic reaction at the active site $\mathrm{C}$ consuming a reactant $\mathrm{R}$ and forming a product $\mathrm{P}$. Kinetic models based on this mechanism are well supported by experiments [7].

The most plausible model of electrochemical promotion, illustrated in Fig. $3 \mathrm{~b}$, is based on analogous donor-acceptor interactions [2][3][8]. Consider the example of anodic polarization of the catalyst. In this case, the donor is the solid electrolyte, supplying $\mathrm{O}^{2-}$ ions toward the catalyst (acceptor). (This migration from support to catalyst may be called backspillover in order to distinguish it from the migration in opposite direction, usual in catalysis and termed spillover.) The $\mathrm{O}^{2-}$ ions are released from the solid electrolyte at the three-phase boundaries (tpb). They may either be consumed along, or near, the tpb in electrochemical reactions (oxygen evolution and/or oxidation of adsorbed reactants) obviously obeying to Faraday's law, or they may spill over the gas-exposed catalyst surface. The driving force of this migration is the difference in the electrochemical potential of $\mathrm{O}^{2-}$ ions between catalyst and solid electrolyte due to polarization of the catalyst [9]. The existence of backspillover oxygen ions at the gas-exposed catalyst surface was demonstrated by XPS measurements [10]. No charged oxygen species were detected under opencircuit conditions but they were found in abundance after anodic polarization of the catalyst/solid electrolyte interface. Charged backspillover oxygen and neutral chemisorbed oxygen may be clearly distinguished also by temperature-programmed desorption (TPD) [11]. It was shown that the oxygen adsorbed from the gas phase desorbs at lower temperature, hence it is more reactive than the electrochemically generated oxygen specimen.

During migration over the gas-exposed catalyst surface, the oxygen ions are accompanied by their compensating image charge in the catalyst, thus forming surface dipoles. Population of the surface with dipoles, i.e. formation of an electric double layer, increases the surface potential hence also the catalyst work function, which is a measurable quantity. In fact, work function measurements, performed also in our laboratory [12], are a useful tool to investigate the
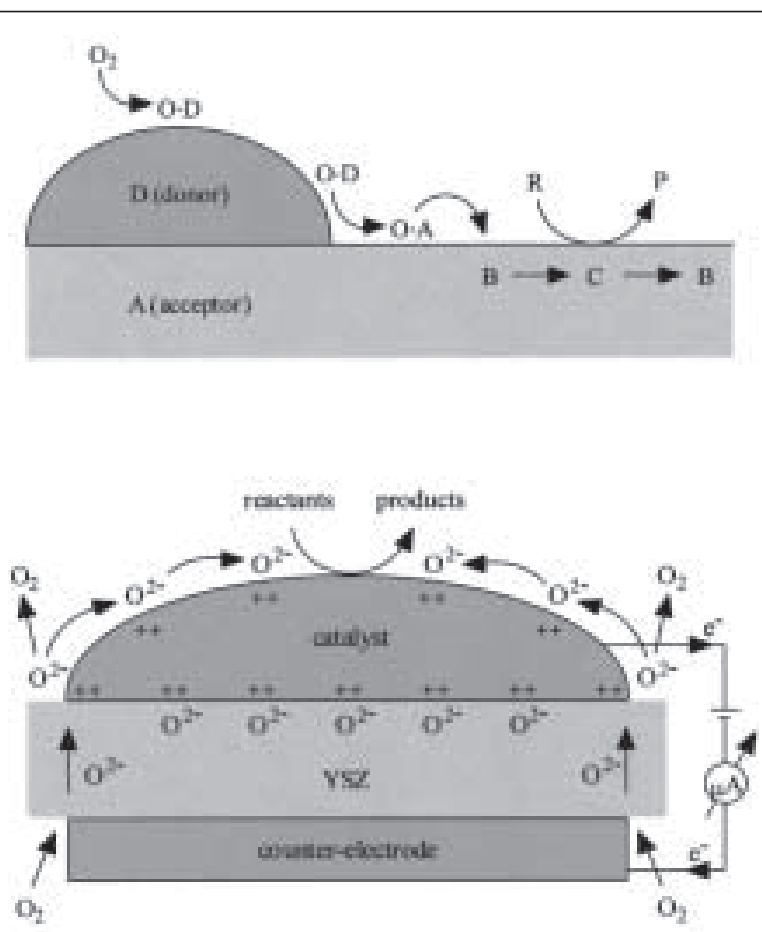
phenomenon of EP. Any change in work function affects the binding strength of chemisorbed reactants. Namely, the adsorption energy of electron acceptors (e.g. atomic $\mathrm{O})$ is weakened, while that of electron donors $\left(\right.$ e.g. $\left.\mathrm{C}_{2} \mathrm{H}_{4}\right)$ is strengthened. Then, a consequent modification in catalytic reaction rates is evident. This picture of the electrochemical promotion is well supported by in situ cyclic voltametry [13] and by the transient behavior of the promoted reaction rate [14].

In summary, electrochemical promotion may be regarded as catalysis at an electric double layer controlled by current or potential application. The necessary condition to achieve electrochemical promotion is the formation of a double layer at the catalyst/gas interface by mechanism of ion backspillover from the solid electrolyte support. This may occur over a wide range of conditions. The most important experimental parameters, which favour electrochemical promotion, are the following: long tpb (porous catalyst), moderate diffusion length (thin catalyst film), and adequate temperature range, e.g. $250-500{ }^{\circ} \mathrm{C}$ for YSZ (a temperature not too low to have enough mobility, and not too high to avoid high reactivity of backspillover ions).

\section{Development of Bipolar Electrochemical Cells}

Two types of bipolar electrochemical cell have been developed in our laboratory, a ring-shaped and a multi-channel configuration. As shown in Fig. 2, both configurations were of cylindrical shape with two gold feeder electrodes on the outside jacket of the YSZ cylinder and with a catalyst film inside, i.e. on the inner wall of the ring in the first case and on that of 37 parallel axial channels in the second case. The feasibility of EP was successfully demonstrated with both configurations [5]. In this paper, the ringshaped configuration allowing more advanced electrochemical characterization of the cell is presented in detail.

The example is a ring-shaped $\mathrm{Rh} /$ YSZ electrochemical cell prepared with a cylindrical YSZ ring (OD $20 \mathrm{~mm}$, ID $17 \mathrm{~mm}$; height $10 \mathrm{~mm}$ ). The rhodium catalyst film (nominal loading: $1.1 \mathrm{~g} \mathrm{~m}^{-2}$, film thickness: $\sim 0.1 \mu \mathrm{m})$ and the gold electrodes were deposited by thermal decomposition of suitable precursors, as described elsewhere [15]. The two symmetrical gold electrodes on the outer surface were separated from each other by two uncoated bands of $3 \mathrm{~mm}$ width. The polarization of the catalyst film in usual bipolar operation is realized using the two gold films as feeder electrodes. For advanced characterization of the cell, a third electric connection may be added. The latter, connected to the catalyst film itself, enables the performance of measurements also in direct (monopolar) polarization modes. This finds use in determination of the current bypass, which is an important parameter of a bipolar cell.

A model developed for electrode stacks with liquid electrolytes [16] was adapted for the estimation of current bypass in the ring-shaped electrochemical cell [17]. The method needs the knowl- edge of the steady-state polarization (current-voltage) curves in three different polarization modes, shown in Fig. 4: direct cathodic (DC) polarization of the catalyst film relative to gold electrode 1 , direct anodic (DA) polarization of the catalyst film with respect to gold electrode 2, and indirect bipolar (IB) polarization between the two terminal gold electrodes, gold 1 being the anode and gold 2 the cathode. The method is based on the additivity of the potential at a given current in the linear (ohmic) region, so the current bypass is measured by the excess of the sum of cell voltages in the two monopolar polarization modes over the cell voltage in the bipolar polarization mode. The fraction of current bypass, $\Psi$, at a given current is then calculated with the following expression:

$$
\Psi=\frac{\left(V_{\mathrm{DC}}+V_{\mathrm{DA}}\right)-V_{\mathrm{IB}}}{\left(V-V_{0}\right)_{\mathrm{DC}}+\left(V-V_{0}\right)_{\mathrm{DA}}}
$$

where $V$ are cell potentials measured at the same current in the linear region, and $V_{\mathrm{o}}$ are overvoltages in the monopolar polarization modes extrapolated to zero current.

The steady-state polarization curves of the cell exhibited an almost perfect additivity [5], see the example at $375^{\circ} \mathrm{C}$ in Fig. 5. Consequently, very low current bypass was obtained calculating with Eqn. 2. It was found fairly independent of the current, but it rose slightly with temperature (from $2-4 \%$ at $350{ }^{\circ} \mathrm{C}$ to $5-6 \%$ at $400{ }^{\circ} \mathrm{C}$ ). Being a necessary condition to achieve efficient electrochemical promotion in bipolar cells, realization of a
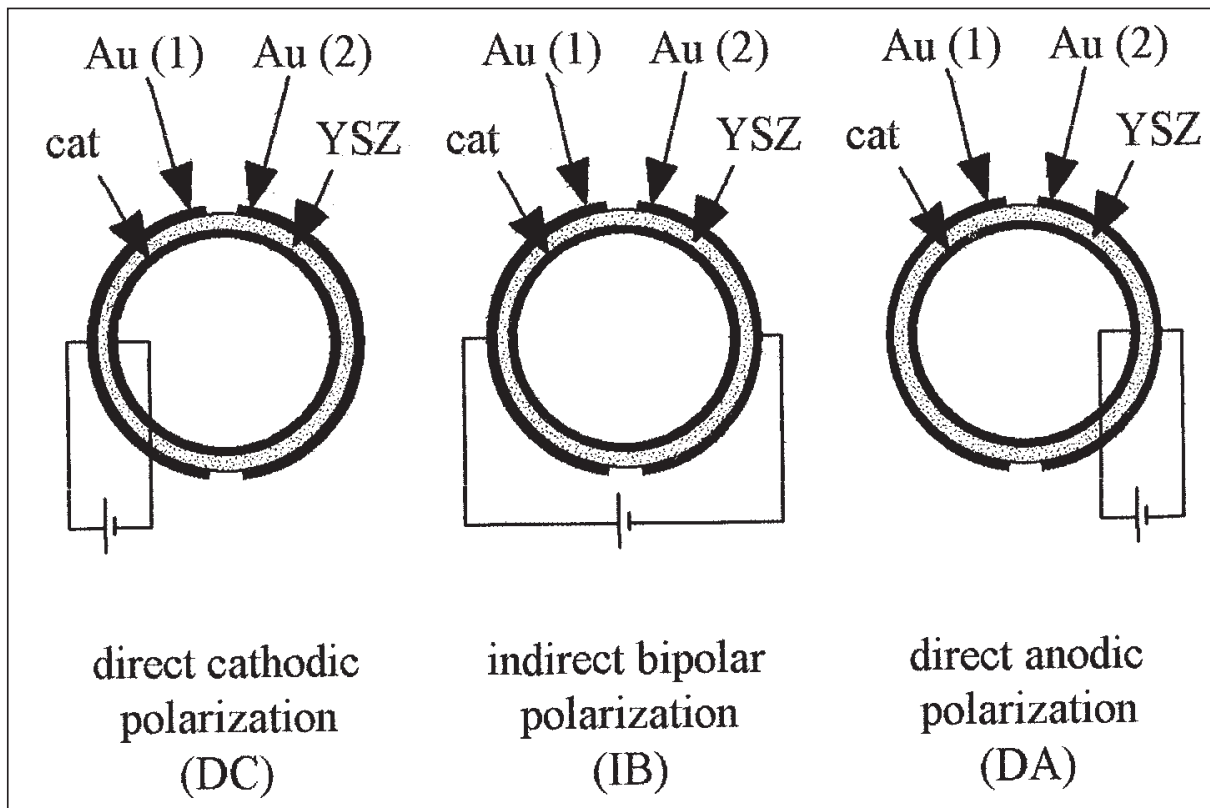

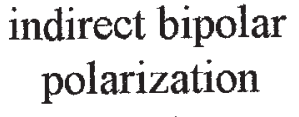

(IB)
Fig. 4. Scheme of various modes of polarization using the ring-shaped electrochemical cell. 
Fig. 5. Current-potential curves of the ringshaped $\mathrm{Rh} / \mathrm{YSZ}$ cell at different polarization modes. $\bigcirc$ : direct cathodic (DC); $\triangle$ : direct anodic $(\mathrm{DA}) ; \diamond: \mathrm{DC}+\mathrm{DA} ; \diamond$ : indirect bipolar (IB). $V_{\text {cell }}$ : cell potential between the two feeder electrodes. $T=375^{\circ} \mathrm{C}$.

nearly bypass-free bipolar configuration is of great importance.

The feasibility of electrochemical promotion with ring-shaped cells will be illustrated with the example of the reduction of NO by propylene in presence of oxygen over rhodium catalyst. Metallic rhodium is known to be an efficient catalyst for the reduction of NO [18][19]. The propylene-NO-oxygen system may serve as a model for the removal of nitrogen oxides $\left(\mathrm{NO}_{\mathrm{x}}\right)$ and hydrocarbons (HC) from auto exhaust gases aiming to transform, under lean fuel conditions, both the reducing pollutants $(\mathrm{HC})$ and the oxidizing pollutants $\left(\mathrm{NO}_{\mathrm{x}}\right)$ into harmless products such as $\mathrm{N}_{2}, \mathrm{CO}_{2}$ and $\mathrm{H}_{2} \mathrm{O}$ (Eqn. 3):

$$
18 \mathrm{NO}(\mathrm{g})+2 \mathrm{C}_{3} \mathrm{H}_{6}(\mathrm{~g}) \rightarrow 9 \mathrm{~N}_{2}(\mathrm{~g})+6 \mathrm{CO}_{2}(\mathrm{~g})+6 \mathrm{H}_{2} \mathrm{O}(\mathrm{g})
$$

$$
18 \mathrm{NO}(\mathrm{g})+\mathrm{C}_{3} \mathrm{H}_{6}(\mathrm{~g}) \rightarrow 9 \mathrm{~N}_{2} \mathrm{O}(\mathrm{g})+3 \mathrm{CO}_{2}(\mathrm{~g})+3 \mathrm{H}_{2} \mathrm{O}(\mathrm{g})
$$

$$
2 \mathrm{C}_{3} \mathrm{H}_{6}(\mathrm{~g})+9 \mathrm{O}_{2}(\mathrm{~g}) \rightarrow 6 \mathrm{CO}_{2}(\mathrm{~g})+6 \mathrm{H}_{2} \mathrm{O}(\mathrm{g})
$$

In competition with the desired reaction, two reactions may prevent efficient reduction of $\mathrm{NO}_{\mathrm{x}}$ : the partial reduction of $\mathrm{NO}$ producing $\mathrm{N}_{2} \mathrm{O}$ (Eqn. 4) and consumption of $\mathrm{HC}$ via direct oxidation in the presence of excess $\mathrm{O}_{2}$ (typical for exhaust gases from lean-burn engines) (Eqn. 5).

The aim is now to induce modification of the catalytic activity of rhodium in this complex system by potential or current application.

The catalytic performance of the ringshaped Rh/YSZ electrode was tested at $375^{\circ} \mathrm{C}$ at varying feed compositions and polarization potentials. Fig. 6 shows the results obtained with feed composition of $\mathrm{C}_{3} \mathrm{H}_{6}(0.25 \mathrm{kPa}) / \mathrm{NO}(0.5 \mathrm{kPa}) / \mathrm{O}_{2}$ $(0.5 \mathrm{kPa})$. Polarization of the rhodium film was made by applying constant cell potentials: $5 \mathrm{~V}$ in the direct polarization modes (DC and DA) and $10 \mathrm{~V}$ in the indirect bipolar polarization mode (IB). It is seen that electrochemical promotion was successful in all polarization modes multiplying the conversion, $X$, of $\mathrm{C}_{3} \mathrm{H}_{6}$ and NO (both about $10 \%$ under open-circuit conditions) with a factor of 2-2.5 in DC and DA modes and with a factor of 3-4 in IB mode. Interestingly, polarization in both monopolar modes was efficient and resulted in an almost identical promotion, independently of the sign of polarization. This is a further argument to affirm that electrochemical promotion is not a Faradaic effect. In fact, the reaction exhibits inverted volcano (minimum rate) type behavior [3] because the kinetics is positive order in both the electron acceptor $(\mathrm{NO})$ and electron donor $\left(\mathrm{C}_{3} \mathrm{H}_{6}\right)$ reactants. In these experiments, not only the feasibility of EP with bipolar polarization was demonstrated but also this mode of polarization was found to be the most efficient. The indirect bipolar polarization, when one half of the catalyst film is ca- thodically and the other half of it is anodically polarized, gave rise to a promotion twice as high as obtained in the direct polarization modes due to the nearly bypass-free cell configuration.

The obtained promotion obviously depends on the applied potential and on the polarizing current. Fig. 7 shows the evolution of $\mathrm{C}_{3} \mathrm{H}_{6}$ and $\mathrm{NO}$ conversion under indirect bipolar (IB) polarization as a function of the cell potential $\left(V_{\text {cell }}\right)$ and of the total current $(I)$ fed by the two gold electrodes. The minimum cell potential required to induce significant electrochemical promotion was $2-3 \mathrm{~V}$ and the promotion leveled off at $6-7 \mathrm{~V}(\sim 1 \mathrm{~mA})$ where the current-voltage curve of the cell enters the region of purely ohmic behavior, see Fig. 5.

Achievement of a significant electrochemical promotion effect in bipolar cells is very promising in view of future applications of the phenomenon with dispersed catalysts.

\section{Conclusions}

The results clearly demonstrate the feasibility of electrochemical promotion with bipolar electrochemical cells. In future work, the development of dispersed 
Fig. 6. Steady-state conversion, $X$, of $\mathrm{C}_{3} \mathrm{H}_{6}$ (left) open-circuit condition $(\mathrm{OC})$ and at three different potentiostatic polarization modes: direct cathodic (DC; $-5 \mathrm{~V})$, direct anodic (DA; $+5 \mathrm{~V}$ ), and indirect bipolar (IB; 10V). The corresponding current is also given. Feed composition and temperature as indicated. $\dot{\nu}=200 \mathrm{ml} \mathrm{min}^{-1}$ STP.

Fig. 7. Effect of the cell potential, $V_{\text {cell }}($ left $)$, and of the total current, I (right), on the conversion, $X$, of $\mathrm{C}_{3} \mathrm{H}_{6}$ and NO under indirect bipolar (IB) polarization in the ring-shaped $\mathrm{Rh} / \mathrm{YSZ}$ cell. Feed composition, gas flow and temperature as in Fig. 6. and $\mathrm{NO}$ (right) in the ring-shaped $\mathrm{Rh} / \mathrm{YSZ}$ cell at
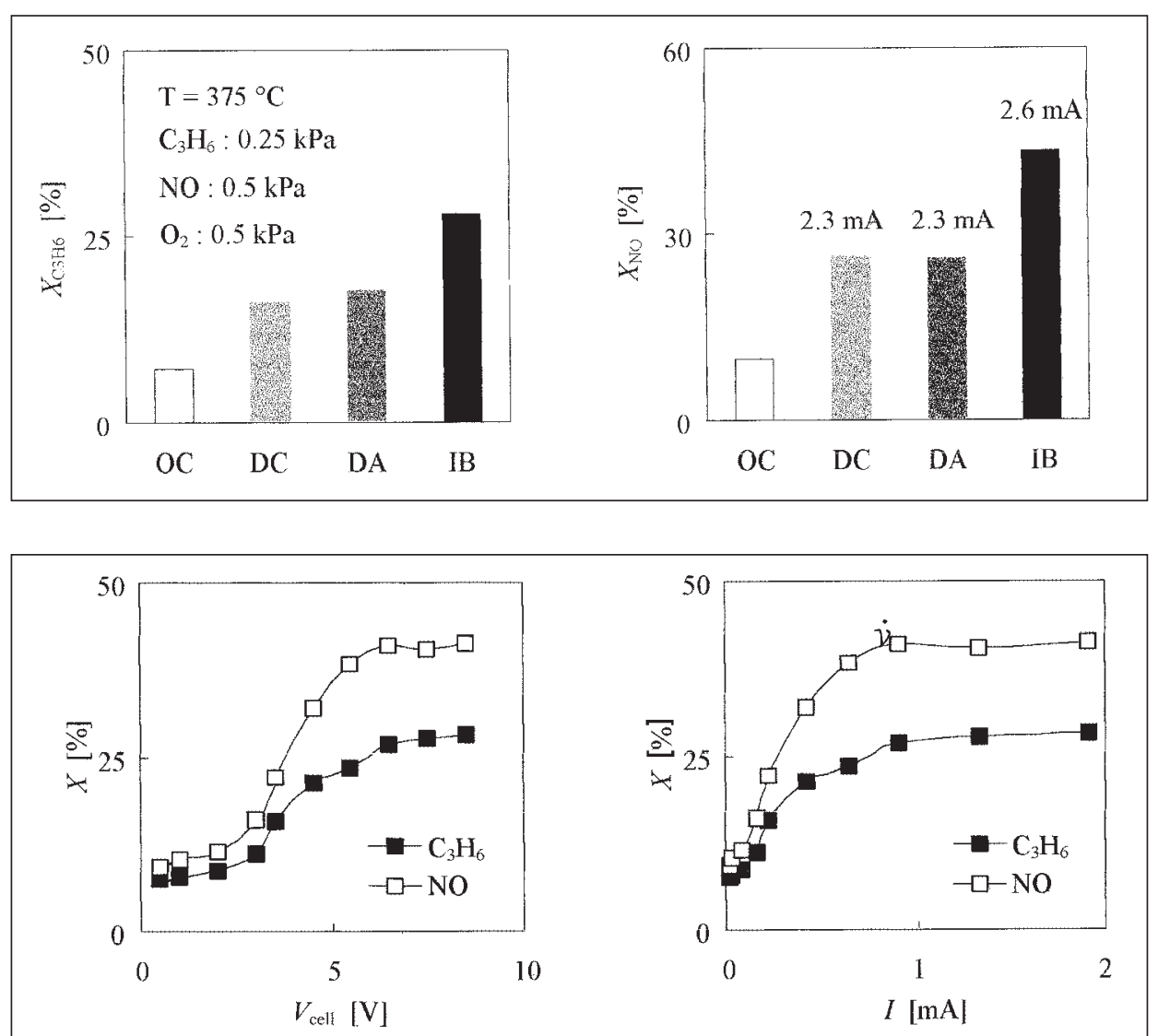

[1] C.G. Vayenas, S. Bebelis, S.G. Neophytides, J. Phys. Chem. 1988, 92, 5083.

catalyst systems for electrochemical promotion should become a major practical goal. The actual progress, ranging from single-pellet cells to various bipolar configurations either with a single bipolar element (ring-shaped cell) or with multiple bipolar elements (multiple-channel cell), may be extended to a dispersed system. A possible way in this direction is the use of porous solid electrolytes as support, the catalyst being deposited in form of a discontinuous film in the pores of the support. Another possible way to achieve electrochemical promotion in dispersed systems consists of fabrication of microstructured cells. The application of thin catalyst films interfaced with solid electrolytes needs small reactor volumes, hence needs also the development of suitable microreactors. In both cases, high cell potentials are expected and careful optimisation is required in order to avoid excessive current bypass.

\section{Acknowledgements}

Financial supports from the Fonds national suisse de la recherche scientifique and from the Office fédéral suisse de l'éducation et de la science are gratefully acknowledged.
[2] C.G. Vayenas, M.M Jaksic, S. Bebelis, S.G. Neophytides, in 'Modern Aspects of Electrochemistry', Vol. 29, Eds. J. O’M. Bockris, B. E. Conway, R. E. White, Plenum Press, New York, 1996, 57.

[3] C.G. Vayenas, S. Bebelis, C. Pliangos, S. Brosda, D. Tsiplakides, 'Electrochemical Activation of Catalysis: Promotion, Electrochemical Promotion and Metal-Support Interactions', Kluwer/Plenum Press, New York, 2002.

[4] J. Nicole, C. Comninellis, J. Appl. Electrochem. 1998, 28, 223.

[5] G. Fóti, S. Wodiunig, C. Comninellis, in 'Current Topics in Electrochemistry', Vol. 7, Research Trends, Trivandrum, 2000, p. 1 .

[6] T. Rebitzki, B. Delmon, J.H. Block, AIChE J. 1995, 41, 1543.

[7] F.M. Faus, B. Zhou, H. Matralis, B. Delmon, J. Catal. 1991, 132, 200.

[8] J. Nicole, D. Tsiplakides, C. Pliangos, X.E. Verykios, C. Comninellis, C.G. Vayenas, J. Catal. 2001, 204, 23.

[9] I.S. Metcalf, J. Catal. 2001, 199, 247; I.S. Metcalf, J. Catal. 2001, 199, 259.

[10] S. Ladas, S. Kennou, S. Bebelis, C.G. Vayenas, J. Phys. Chem. 1993, 97, 8845.

[11] S.G. Neophytides, D. Tsiplakides, C.G. Vayenas, J. Catal. 1998, 178, 414.

[12] S. Wodiunig, V. Patsis, C. Comninellis, Solid State Ionics 2000, 136, 813.
[13] J. Nicole, C. Comninellis, Solid State Ionics 2000, 136, 687.

[14] G. Fóti, V. Stanković, I. Bolzonella, C. Comninellis, J. Electroanal. Chem. in press.

[15] C. Comninellis, G.P. Vercesi, J. Appl. Electrochem. 1991, 21, 335.

[16] C. Comninellis, in 'Electrochemical Engineering and Energy', Ed. F. Lapicque, Plenum Press, New York, 1995, p. 177.

[17] Wodiunig, F. Bokeloh, C. Comninellis, Electrochim. Acta 2000, 46, 357.

[18] J.T. Kummer, J. Phys. Chem. 1986, 90, 4747.

[19] K.C. Taylor, Catal. Rev. Sci. Eng. 1993, $35,457$. 